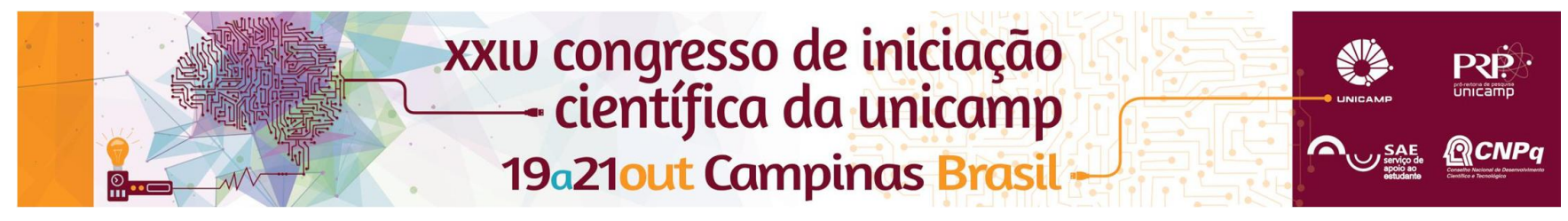

\title{
PROPAGAÇÃO DA RESISTÊNCIA DE CLONES DE EUCALIPTO EM DIFERENTES IDADES.
}

\author{
Luis H. C. Marques*, Raquel Gonçalves, Rafael G. M. Lorensani.
}

\section{Resumo}

Encontra-se em desenvolvimento no Laboratório de Ensaios Não Destrutivos (LabEND) da FEAGRI, projeto de doutorado apoiado pela FAPESP e pela Empresa International Paper do Brasil (IPBr), que visa determinar modelo de previsão da qualidade da madeira em idade de corte a partir de ensaios de propagação de onda em caules de plântulas (mudas) de clones de eucalipto. As propriedades mecânicas estão entre as que deverão ser determinadas em várias idades dos clones, para analisar a evolução desde a muda até a idade de corte. O objetivo desta pesquisa de iniciação científica foi avaliar se a diferenciação de resistência e de rigidez, obtida entre mudas de diferentes espécies clonais, se mantêm ao longo dos anos, até a idade de corte. O delineamento experimental foi composto de amostra com 3 diferentes clones ( $A, B, C)$, dois deles ( $A$ e $B$ ) ensaiados com idades variando de 3 meses (muda) a 72 meses e um deles (C) ensaiado apenas nas idades extremas (3 e 72 meses). Os resultados permitiram concluir que a diferenciação dos clones à partir do ensaio na muda se manteve na árvore em idade de corte quando o parâmetro analisado foi a rigidez, mas não quando o parâmetro foi a resistência.

\section{Palavras-chave: tração paralela à grã, propagação da resistência com a idade, propagação da rigidez com a idade}

\section{Introdução}

O aumento da competitividade do setor madeireiro será dependente da modernização tecnológica que permita realizar a avaliação da qualidade da madeira a partir de árvores ainda na floresta. Quanto mais antecipada for essa caracterização, maiores serão os ganhos de produtividade e de qualidade. Em pesquisa em andamento no Brasil (FEAGRI/UNICAMP), em parceria com empresa florestal (International Paper), os pesquisadores estão avaliando a viabilidade de antecipar a seleção das árvores por meio de ensaios realizados em mudas ou em árvores em estágios iniciais de crescimento. O objetivo desta pesquisa de iniciação científica foi avaliar se a diferenciação de resistência (f) e de rigidez $(E)$, obtida entre mudas de diferentes espécies clonais $(A, B, C)$, se mantêm ao longo dos anos, até a idade de corte (72 meses). Tendo em vista a dimensão, nas mudas de 3 meses a resistência e a rigidez foram determinadas em tração (Figura 1a), enquanto nas árvores de 24 a 72 meses em compressão (Figura 1b), ambos paralelos à grã.

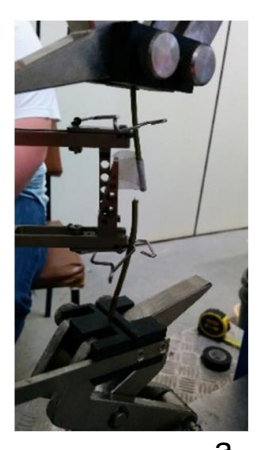

a

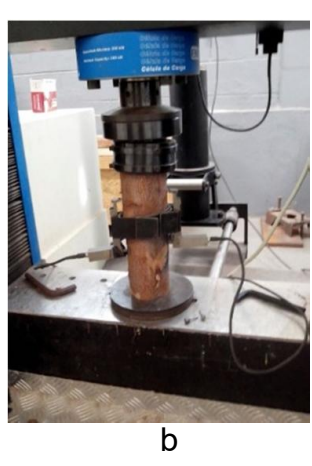

Figura 1. Ensaio de tração em mudas (a) e de compressão em peças retiradas da base das árvores (b)

\section{Resultados e Discussão}

O comportamento geral da resistência (f) dos 3 clones mostra que, desde a muda ( 3 meses) até a idade de corte (72 meses), o crescimento apresenta variações e é menos acentuado (Figura 2a) do que o módulo de elasticidade (E) no mesmo período (Figura $2 b$ ).

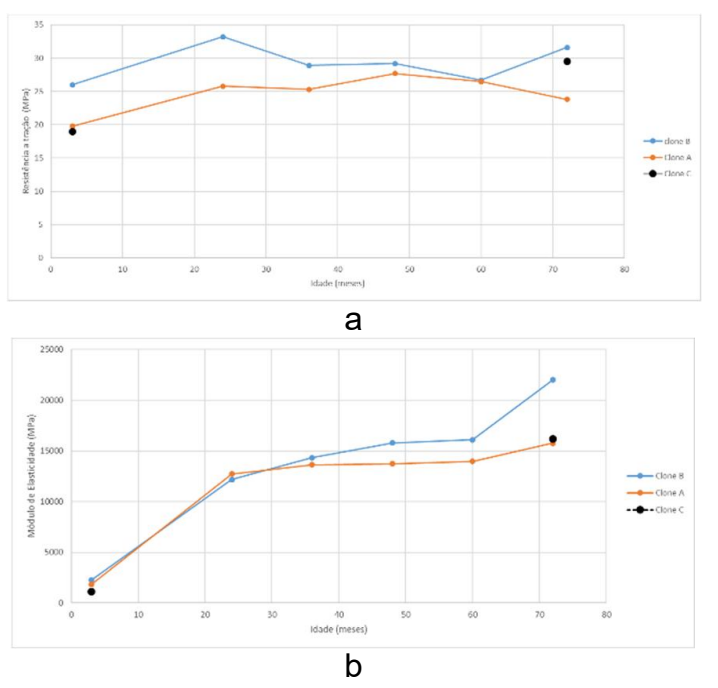

Figura 2. Comportamento da resistência (a) e do módulo de elasticidade (b) ao longo dos anos de crescimento

Estatisticamente, no entanto, em função dos coeficientes de variação, a resistência (f) da muda do clone $C$ foi diferente e menor do que a dos clones $\mathrm{A}$ e $\mathrm{B}$, mas aos 72 meses nenhum clone se diferenciou. Para o módulo de elasticidade $(E)$ o clone $B$ se diferenciou e foi maior do que os outros dois desde a muda até aos 72 meses.

\section{Conclusões}

A diferenciação dos clones à partir do ensaio na muda se manteve na árvore em idade de corte quando o parâmetro analisado foi a rigidez, mas não quando o parâmetro foi a resistência..

\section{Agradecimentos}

Ao CNPq e à FAPESP (2013/03449-9).pelas bolsas de estudo e à International Paper pelo material da pesquisa. 